\title{
Konstruksi dan Validasi Alat Ukur Workplace Well-Being di Indonesia
}

\section{Construction and Validation of Workplace Well-Being Measurement Tools in Indonesia}

\author{
Vianda Maulidina( ${ }^{\left({ }^{*}\right)} \&$ Anissa Lestari Kadiyono(2) \\ Fakultas Psikologi, Universitas Padjadjaran, Indonesia \\ Disubmit: 11 Oktober 2021; Diproses: 12 Oktober 2021; Diaccept: 30 Oktober 2021; Dipublish: 02 Desember 2021 \\ *Corresponding author: E-mail: vianda19001@mail.unpad.ac.id
}

\begin{abstract}
Abstrak
Penelitian dalam mengukur kesejahteraan karyawan di tempat kerja (workplace well-being) semakin banyak dilakukan oleh para peneliti di Indonesia. Page (2005) telah mengembangkan sebuah instrumen untuk melakukan pengukuran workplace well-being yaitu Workplace Well-being Index (WWBI) yang terdiri dari 17 aitem. Sejauh penelusuran peneliti, belum ada penelitian yang secara khusus melakukan pengembangan alat ukur workplace well-being dalam bahasa Indonesia. Oleh karena itu, peneliti bermaksud untuk melakukan konstruksi alat ukur workplace well-being berdasarkan konsep teori Page (2005). Pengujian validitas dan reliabilitas alat ukur ini dilakukan terhadap 102 karyawan tetap yang bekerja pada berbagai bidang perusahaan di Kota Bandung. Adapun teknik analisis yang digunakan adalah metode Confirmatory Factor Analysis (CFA) untuk pengujian validitas konstruk, dan teknik Alpha Cronbach untuk pengujian reliabilitas alat ukur. Berdasarkan penelitian yang telah dilakukan, dapat disimpulkan bahwa hasil konstruksi alat ukur Workplace Well-Being (WWB) yang diajukan dinyatakan valid dan reliabel. Artinya, alat ukur ini dinilai mampu mengukur workplace well-being seorang karyawan dengan tepat dan konsisten, sehingga dapat digunakan untuk penelitian-penelitian selanjutnya.
\end{abstract}

Kata Kunci: Indonesia; Reliabilitas; Validitas Konstruk; Workplace Well-Being

\begin{abstract}
Research in measuring employee well-being in the workplace (workplace well-being) is increasingly being carried out by researchers in Indonesia. Page (2005) has developed an instrument to measure workplace well-being, namely the Workplace Well-being Index (WWBI), which consists of 17 items. As far as researchers search, there is no research that specifically develops workplace well-being measuring tools in Indonesian. Therefore, the researcher intends to construct a workplace well-being measurement tool based on Page's (2005) theory concept. Testing the validity and reliability of this measuring instrument was conducted on 102 permanent employees who work in various fields of companies in the city of Bandung. The analytical technique used is the Confirmatory Factor Analysis (CFA) method for testing construct validity, and Alpha Cronbach technique for testing the reliability of measuring instruments. Based on the research that has been done, it can be concluded that the results of the proposed Workplace Well-Being (WWB) measuring instrument construction are valid and reliable. This means that this measuring tool is considered capable of measuring an employee's workplace well-being accurately and consistently, so that it can be used for further research.

Keywords: Indonesia; Reliability; Construct Validity; Workplace Well-Being
\end{abstract}

DOI: https://doi.org/10.51849/j-p3k.v2i3.119

Rekomendasi mensitasi :

Maulidina, V., \& Kadiyono, A.L.. (2021), Konstruksi dan Validasi Alat Ukur Workplace Well-Being di Indonesia. Jurnal Penelitian Pendidikan, Psikologi dan Kesehatan (J-P3K), 2 (3): 252-258. 


\section{PENDAHULUAN}

Beberapa tahun belakangan ini, topik mengenai pentingnya kesejahteraan karyawan (employee well-being) di tempat kerja seringkali diperbincangkan. Berdasarkan Page \& Vella-Brodrick (2009) terdapat 3 komponen dari konsep kesejahteraan karyawan, yaitu: (1) subjective well-being (kepuasan kehidupan dan dispositional affect); (2) psychological well-being (penerimaan diri, hubungan interpersonal positif, penguasaan lingkungan, otonomi, tujuan hidup, dan perkembangan diri); dan (3) workplace well-being (kepuasan kerja dan hal-hal terkait pekerjaan). Workplace well-being (kesejahteraan karyawan di tempat kerja) merupakan sebuah konsep yang dapat dikatakan cukup baru dikembangkan oleh Page (2005).

Konsep workplace well-being (WWB) adalah komponen aplikasi dari subjective well-being (SWB). SWB merupakan kondisi pikiran yang positif dan melibatkan seluruh pengalaman hidup. Komponen SWB mencakup kepuasan hidup secara umum, afek positif pada tingkat tinggi, dan afek negatif pada tingkat rendah (Diener et al, Suh, Lucas, \& Smith dalam Page, 2005). Menurut Diener (1984 dalam Page, 2005), SWB dapat menjadi sebuah konsep mengenai kepuasan dari berbagai macam domain kehidupan, salah satunya adalah pekerjaan.

Pada tahun 2005, Page melakukan sebuah penelitian berjudul "Subjective Well-Being in the Workplace" yang bertujuan untuk membuktikan bahwa SWB dapat diaplikasikan kepada satu kehidupan utama, yaitu pekerjaan. Berdasarkan penelitian tersebut, ditemukan hasil bahwa SWB dapat dilihat sebagai evaluasi global terhadap kepuasan hidup secara keseluruhan di domain kehidupan tempat kerja, sehingga munculah konstruk workplace well-being. Workplace well-being didefinisikan sebagai perasaan sejahtera yang diperoleh pekerja dari pekerjaan mereka (Page, 2005). Workplace well-being merupakan kombinasi dari perasaan pekerja secara umum pada pekerjaannya (core affect) dan kepuasan pekerja terhadap nilai-nilai pekerjaan (work values).

Core affect merupakan keadaan yang menggambarkan rasa nyaman dan tidak nyaman bercampur dan gairah (passion) yang mempengaruhi aktivitas manusia (Russell dalam Page, 2005). Untuk itu, core affect dapat diartikan sebagai perasaan individu secara umum. Davern et al (2004, dalam Page, 2005) telah membentuk model dari core affect yang terdiri dari sifat contented (menunjukkan rasa puas), happy (senang), excited (bersemangat), dan satisfied (merasa terpenuhi/ terpuaskan). Page (2005) menemukan bahwa apabila keempat sifat tersebut digunakan bersamaan, maka akan mengarahkan kepada suatu objek dengan perasaan puas secara keseluruhan.

Work values, baik intrinsik maupun ekstrinsik, diartikan sebagai derajat keberhargaan, kepentingan, dan hal-hal yang disukai oleh individu di tempat kerja (Knoop, dalam Page, 2005). Work values menunjukkan aspek-aspek pekerjaan yang bermakna bagi karyawan dan dapat membuat mereka menikmati pekerjaannya, sehingga hal ini penting untuk menentukan workplace well-being karyawan. Bertolak dari teori Herzberg 
dan Knoop, K. Page (2005) menjelaskan ada 13 aspek dari workplace well-being yang dibagi ke dalam dua faktor besar, yaitu 5 aspek faktor intrinsik (tanggung jawab dalam pekerjaan, makna kerja, kemandirian dalam bekerja, penggunaan kemampuan dan pengetahuan di pekerjaan, perasaan berprestasi dalam bekerja), dan 8 faktor ekstrinsik (kenyamanan jam kerja, kondisi kerja, supervisi, kesempatan promosi, pengakuan terhadap kinerja yang baik, penghargaan sebagai individu di tempat kerja, upah, keamanan pekerjaan).

Harter et al. (2002) menyatakan well-being karyawan di tempat kerja merupakan sebuah elemen mendasar bagi organisasi, sehingga karyawan berhasil berkontribusi terhadap hasil yang diinginkan seperti peningkatan performance. Kemudian menurut Page (2005), karyawan yang memiliki wellbeing yang tinggi adalah karyawan yang merasakan emosi positif sehingga menjadi lebih bahagia dan lebih produktif. Selain itu, terdapat dampak negatif dari tingkat kesejahteraan pegawai di tempat kerja yang rendah, yaitu seperti rendahnya produktivitas pegawai, sulitnya melakukan decision-making, dan meningkatnya absenteeism (Sawitri et al., 2013). Dengan kata lain, kesejahteraan karyawan menjadi aspek yang harus diperhatikan agar karyawan dapat memberikan performa terbaik untuk mencapai tujuan perusahaan, terutama meningkatkan employee performance (Kathryn M. Page \& Vella-Brodrick, 2009).

Pengembangan alat ukur yang valid dan reliabel untuk melakukan pengukuran mengenai workplace well-being penting dilakukan, mengingat isu mengenai workplace well-being cukup banyak diteliti. Page (2005) telah mengembangkan sebuah instrumen untuk melakukan pengukuran workplace wellbeing yaitu Workplace Well-being Index (WWBI) yang terdiri dari 17 aitem. Setelah WWBI digunakan beberapa kali dalam penelitian, ditemukan tingkat internal consistency yang sangat baik yaitu rata-rata sebesar 0.94 (Page, 2010). Akan tetapi, jika melihat beberapa penelitian mengenai workplace well-being yang telah dilakukan di Indonesia, sejauh penelusuran peneliti belum ada penelitian yang secara khusus melakukan pengembangan alat ukur workplace wellbeing berbahasa Indonesia. Oleh karena itu, peneliti tertarik untuk melakukan penelitian yang berfokus pada proses konstruksi dan validasi alat ukur workplace well-being berdasarkan konstruk dari Page (2005) dalam versi bahasa Indonesia.

\section{METODE PENELITIAN}

Metode penelitian yang digunakan adalah penelitian kuantitatif, dengan teknik pengumpulan data menggunakan self-report measurement yaitu kuesioner dalam bentuk google form yang disebarkan secara daring melalui media sosial. Penelitian ini melibatkan sebanyak 102 karyawan tetap yang bekerja pada berbagai bidang perusahaan yang meliputi perbankan, telekomunikasi, pengiriman paket, farmasi, busana, serta beberapa jenis perusahaan lainnya. Pemilihan responden pada penelitian ini dilakukan menggunakan teknik non-probability sampling, yang sebagian besar responden merupakan karyawan yang berlokasi di Kota Bandung. 
Alat ukur pada penelitian ini dikembangkan oleh peneliti berdasarkan konstruk teori Workplace Well-Being dari Page (2005). Awalnya alat ukur yang sudah ada yaitu Workplace Well-Being Index (WWBI) memiliki 17 aitem pertanyaan, dan kemudian dikembangkan peneliti menjadi 56 aitem. Alat ukur WWBI mengukur tiga dimensi dari workplace well-being, yaitu seberapa puas karyawan terhadap pekerjaannya secara umum (core affect) dan terhadap nilainilai intrinsik maupun ekstrinsik dari pekerjaannya (work values intrinsic \& extrinsic). Alat ukur ini dibagi menjadi 2 bagian kuesioner yang berbeda antara core affect dan work values.

Aitem pernyataan yang ada di dalam alat ukur WWB hanya memiliki satu sifat aitem yaitu aitem positif (favourable), dengan skala pengukuran yang digunakan adalah Skala Likert. Alat ukur ini memiliki empat pilihan jawaban, yaitu (1) Tidak Sesuai/ Tidak Puas, (2) Kurang Sesuai/ Kurang Puas, (3) Agak Sesuai/ Agak Puas, (4) Sesuai/ Puas. Responden diminta memilih jawaban yang sesuai dengan kondisi mereka yang dialami di tempat kerja mereka.

Tabel 1. Kisi-Kisi Alat Ukur Workplace Well-Being

\begin{tabular}{|c|c|c|}
\hline Dimensi & No Aitem & $\begin{array}{c}\text { Jumlah } \\
\text { Aitem }\end{array}$ \\
\hline Core Affect & $1,2,3,4$ & 4 \\
\hline $\begin{array}{l}\text { Work Values } \\
\text { Intrinsic }\end{array}$ & $\begin{array}{l}1,2,3,4,5,6,7,8, \\
9,10,11,12,13, \\
14,15,16,17,18, \\
19,20\end{array}$ & 20 \\
\hline $\begin{array}{l}\text { Work Values } \\
\text { Extrinsic }\end{array}$ & $\begin{array}{l}21,22,23,24,25, \\
26,27,28,29,30, \\
31,32,33,34,35, \\
36,37,38,39,40, \\
41,42,43,44,45, \\
46,47,48,49,50, \\
51,52\end{array}$ & 32 \\
\hline Total Aitem & & 56 Aitem \\
\hline
\end{tabular}

Berdasarkan Tabel 1, dapat dilihat bahwa alat ukur Workplace Well-Being pada penelitian ini terdiri dari 56 aitem. Aitem-aitem ini meliputi aitem tambahan yang peneliti susun secara mandiri berdasarkan definisi konseptual masingmasing dimensi workplace well-being dari Page (2005), dan disempurnakan oleh dua orang expert review. Adapun contoh aitem dari setiap dimensi workplace well-being tercantum pada tabel di bawah ini:

Tabel 2. Contoh Aitem Alat Ukur Workplace WellBeing

\begin{tabular}{ll} 
Dimensi & \multicolumn{3}{c}{ Contoh Aitem } \\
\hline Core Affect & $\begin{array}{l}\text { Secara keseluruhan, saya merasa } \\
\text { puas dengan pekerjaan saya di } \\
\text { tempat saya bekerja }\end{array}$ \\
\hline $\begin{array}{l}\text { Work } \\
\text { Values }\end{array}$ & $\begin{array}{l}\text { Seberapa puas saya terhadap } \\
\text { tanggung jawab yang saya miliki } \\
\text { Intrinsic }\end{array}$ \\
\hline $\begin{array}{l}\text { dalam bekerja? } \\
\text { Values }\end{array}$ & $\begin{array}{l}\text { Seberapa puas saya terhadap jam } \\
\text { Extrinsic }\end{array}$ \\
\hline
\end{tabular}

Teknik analisis yang digunakan dalam penelitian ini adalah metode Confirmatory Factor Analysis (CFA) untuk memastikan construct validity alat ukur yang dikembangkan. Kemudian model konstruk variabel yang diuji dalam penelitian ini menggunakan analisis latent variables yaitu berdasarkan total score dari tiga dimensi workplace well-being yang meliputi core affect, work values intrinsic dan work values extrinsic. Metode CFA ini akan dilakukan menggunakan software Lisrel 8.8.

Evaluasi kesesuaian model pengukuran dalam CFA ini dapat dilihat dari beberapa indeks goodness of fit indices (GFI), yaitu nilai Chi-Square $\left(\chi^{2}\right)$, Comparative Fit Index (CFI), Root Mean Square Error of Approximation (RMSEA), dan Standardized Root Mean Square Residual (SRMR) yang tercantum dalam 
Tabel 3. Apabila telah memenuhi minimal dua persyaratan tersebut, maka model pengukuran yang diuji dapat dikatakan fit. Adapun kriteria valid dalam analisis CFA yaitu jika loading factor $>0.30$ (Iskandar, 2017).

Tabel 3. Kriteria Indeks GFI

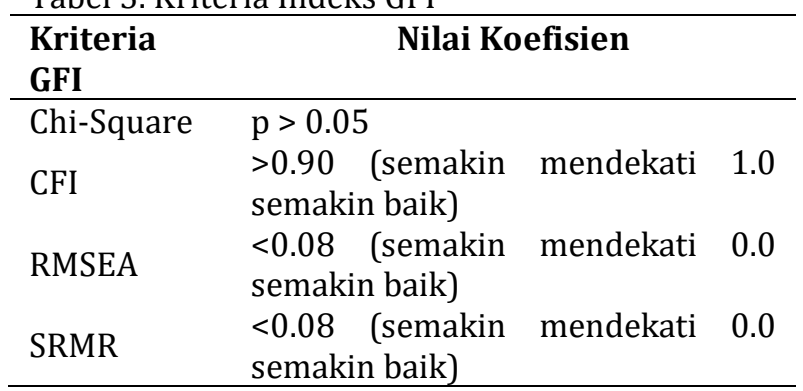

Sumber: Brown (2015)

Selain melakukan uji validitas konstruk, peneliti juga melakukan uji reliabilitas guna memastikan konsistensi instrumen pengukuran dalam mengukur setiap konstruk. Pengujian reliabilitas alat ukur dilakukan dengan teknik Cronbach's Alpha dengan bantuan SPSS Statistics Version 25.0. Adapun kriteria tingkat reliabilitas menurut Guilford yaitu:

Tabel 4. Kriteria Reliabilitas Alat Ukur

\begin{tabular}{cl}
\hline $\begin{array}{l}\text { Nilai } \\
\text { Koefisien } \\
\text { Cronbach's Alpha }\end{array}$ & Tingkat Reliabilitas \\
\hline$\leq 0.20$ & Sangat Rendah \\
$0.21-0.40$ & Rendah \\
$0.41-0.60$ & Sedang \\
$0.60-0.80$ & Tinggi \\
$0.80-1.00$ & Sangat Tinggi \\
\hline \multicolumn{2}{l}{ Sumber: Noor (2012) }
\end{tabular}

\section{HASIL DAN PEMBAHASAN}

Kuesioner workplace well-being yang dikembangkan oleh peneliti, terdiri dari 56 aitem yang dibagi menjadi dua bagian. Bagian 1 merupakan kuesioner untuk mengukur dimensi core affect yang terdiri dari 4 aitem. Bagian 2 mengukur dimensi work values yang terdiri dari 20 aitem untuk work values intrinsic dan 32 aitem work values extrinsic.

\section{Uji Validitas}

Hasil uji validitas yang telah dilakukan menggunakan metode CFA dengan teknik analisis latent variables, diperoleh hasil sebagai berikut:

\begin{tabular}{lcccc} 
Tabel 5. Hasil Confirmatory Factor Analysis \\
\hline & \multicolumn{4}{c}{ Goodness of Fit } \\
\cline { 2 - 5 } & $\begin{array}{l}\text { Chi-Square } \\
\left(\boldsymbol{p} \text { of } \boldsymbol{x}^{2} / \boldsymbol{d} \boldsymbol{f}\right)\end{array}$ & CFI & RMSEA & SRMR \\
\hline Skor & 1.00 & - & 0.000 & - \\
\hline Evaluasi & Good & - & Good & - \\
\hline
\end{tabular}

\section{Berdasarkan hasil CFA terhadap 56} aitem workplace well-being, dapat dilihat bahwa data yang diperoleh fit dengan model yang diajukan. Hal tersebut dikarenakan nilai koefisien chi-square memperoleh nilai $>0.05$ yang menunjukkan angka skor yang good/ideal. Kemudian diperoleh pula indeks fit lainnya yaitu RMSEA dengan nilai koefisien $<0.08$. Oleh karena itu, model alat ukur workplace well-being ini mengindikasikan bahwa model dapat diterima.

Selain melihat kecocokan model yang diajukan, peneliti juga melihat nilai koefisien standar yang diperoleh pada setiap total score dimensi. Nilai ini menunjukkan seberapa besar suatu dimensi berkontribusi dalam mengukur suatu konstruk, dimana semakin besar nilai koefisien yang diperoleh, maka semakin baik dimensi tersebut dalam mengukur konstruk tersebut. Nilai koefisien standar pada masing-masing dimensi dapat dilihat pada Gambar 1. 


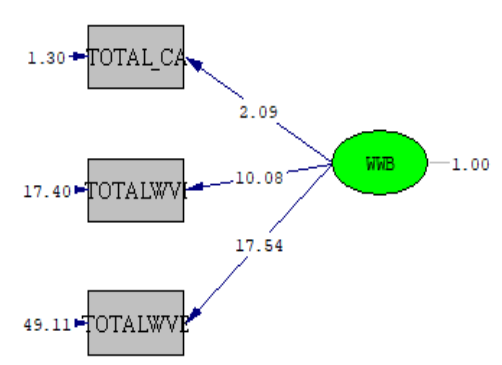

Chi-Square $=0.00, d f=0, p-$ value $=1.00000$, RMSEA $=0.000$

Gambar 1. Path Diagram Model Tiga Dimensi WWB

Berdasarkan Gambar 1, diketahui bahwa tidak ada nilai koefisien yang bermuatan negatif. Diperoleh pula loading factor dari masing-masing dimensi memiliki nilai >0.30. Hal ini dapat mengindikasikan bahwa secara keseluruhan, ketiga dimensi dalam model ini dapat berkontribusi dengan baik dalam mengukur konstruk workplace well-being.

\section{Uji Reliabilitas}

Hasil uji reliabilitas yang telah dilakukan menggunakan internal consistency reliability berdasarkan nilai koefisien Cronbach's Alpha, diperoleh hasil sebagai berikut:

Tabel 6. Hasil Reliabilitas Alat Ukur

\begin{tabular}{cc}
\hline Dimensi & $\begin{array}{c}\text { Nilai Koefisien } \\
\text { Cronbach's Alpha }\end{array}$ \\
\hline Core Affect & 0.879 \\
\hline Work Values Intrinsic & 0.960 \\
\hline Work Values Extrinsic & 0.963 \\
\hline
\end{tabular}

Berdasarkan Tabel 6, dapat dilihat bahwa alat ukur workplace well-being memiliki reliabilitas yang sangat baik. Hal tersebut ditunjukkan dengan nilai koefisien Cronbach's Alpha pada setiap dimensi di atas 0.80. Kemudian diperoleh juga hasil reliabilitas alat ukur workplace well-being secara keseluruhan dengan nilai 0.979, yang menunjukkan bahwa model alat ukur yang diajukan memiliki tingkat konsistensi yang baik dalam mengukur konstruk workplace well-being.

Dengan demikian, seluruh aitem yang telah diadaptasi dan diuji terhadap 102 sampel karyawan, telah sesuai dengan model tiga dimensi workplace well-being yang diuraikan berdasarkan kontruk teori dari Page (2005). Adapun perbedaan alat ukur yang diusulkan dalam penelitian ini dengan alat ukur yang sudah ada sebelumnya adalah terdapat aitem tambahan sebanyak 39 aitem yang peneliti susun berdasarkan konstruk teori workplace well-being dari Page (2005). Selain itu, aitem-aitem yang ada telah diterjemahkan ke dalam Bahasa Indonesia dan disesuaikan dengan kondisi budaya Indonesia, sehingga alat ukur dapat digunakan untuk mengukur workplace well-being karyawan di Indonesia.

\section{SIMPULAN}

Berdasarkan penelitian yang telah dilakukan, dapat disimpulkan bahwa hasil konstruksi alat ukur Workplace Well-Being (WWBI) yang diajukan dinyatakan valid dan reliabel. Artinya, hasil adaptasi alat ukur ini dinilai mampu mengukur workplace well-being seorang karyawan dengan tepat dan konsisten, sehingga dapat digunakan untuk penelitianpenelitian selanjutnya.

Adapun, keterbatasan dari penelitian ini adalah jumlah partisipan yang kurang yaitu hanya sejumlah 102 karyawan. Kemudian pemilihan partisipan yang hanya berada di Kota Bandung, sehingga kurang merepresentasikan kondisi karyawan di kota-kota lainnya. Hal ini sebaiknya dapat menjadi pertimbangan 
bagi penelitian berikutnya agar menjangkau partisipan yang lebih banyak dan beragam agar lebih representatif.

\section{DAFTAR PUSTAKA}

Brown, T. A. (2015). Confirmatory Factor Analysis for Applied Research (Second). The Guilford Press.

Burns, R. A., \& Machin, M. A. (2013). Employee and Workplace Well-being: A Multi-level Analysis of Teacher Personality and Organizational Climate in Norwegian Teachers from Rural, Urban and City Schools. Scandinavian Journal of Educational Research, 57(3), 309-324. https://doi.org/10.108o/o0313831.2012.65628 1

Davern, M. T., Cummins, R. A., \& Stokes, M. A. (2007). Subjective wellbeing as an affectivecognitive construct. Journal of Happiness Studies, $\quad 8(4), \quad$ 429-449. https://doi.org/10.1007/s10902-007-9066-1

Diener, E. (2009). Assessing Well-Being. The Collected Works of Ed Diener. In Springer. https://doi.org/10.1007/978-90-481-2354-4

Diener, E., Oishi, S., \& Lucas, R. E. (2012). Subjective Well-Being: The Science of Happiness and Life Satisfaction. The Oxford Handbook of Positive Psychology, (2 Ed.), February 2019, 1-16. https://doi.org/10.1093/oxfordhb/978019518 7243.013.0017

Fridayanti, Kardinah, N., \& Nurul Fitri, T. J. (2019). Peran Workplace Well-being terhadap Mental Health: Studi pada Karyawan Disabilitas. Psympathic: Jurnal Ilmiah Psikologi, 6(2), 191-200. https://doi.org/10.15575/psy.v6i2.5754

Harter, J. K., Schmidt, F. L., \& Keyes, C. L. M. (2002). Well-being in the workplace and its relationship to business outcomes: A review of the Gallup studies. Flourishing: Positive Psychology and the Life Well-Lived., January, https://doi.org/10.1037/10594-009

Helliwell, J. F., \& Barrington-Leigh, C. P. (2010). Viewpoint: Measuring and understanding subjective well-being. Canadian Journal of Economics, 43(3), 729-753. https://doi.org/10.1111/j.15405982.2010.01592.X

Herzberg, F. (1987). One More Time: How Do You Motivate Employees? In Harvard Business
Review. President and Fellows of Harvard College.

Iskandar, A. (2017).Teknik Analisis Validitas Konstruk dan Reliabilitas Instrument Test dan Non Test dengan Software LISREL. https://doi.org/10.31227/ osf.io/nbhxq

Knoop, R. (1994). Work values and job satisfaction. Journal of Psychology: Interdisciplinary and Applied, 128(6), 683690.

https://doi.org/10.108o/oo223980.1994.9921 297

Noor, Hasanuddin. (2012). Psikometri: aplikasi dalam penyusunan instrumen pengukuran perilaku. Bandung: Jauhar Mandiri.

Page, K. (2005). Subjective Wellbeing in the Workplace [Deakin University]. https://doi.org/10.12968/prma.2016.26.8.40

Page, Kathryn M., \& Vella-Brodrick, D. A. (2009). The "what", "why" and "how" of employee well-being: A new model. Social Indicators Research, 90(3), 441-458. https://doi.org/10.1007/s11205-0o8-9270-3

Page, Kathryn May. (2010). Working for wellness: defining, measuring, and enhancing employee well-being. Monash University.

Pavot, W., \& Diener, E. (2004). The subjective evaluation of well-being in adulthood: Findings and implications. Ageing International, 29(2), 113-135. https://doi.org/10.1007/s12126-004-1013-4

Proctor, C. (2014). Subjective Well-being. Positive Psychology Research Centre, 6437-6440. https://doi.org/10.1007/978-94-007-0753-5

Russell, J. A. (2003). Core Affect and the Psychological Construction of Emotion. Psychological Review, 110(1), 145-172. https://doi.org/10.1037/0033-295X.110.1.145

Sawitri, D. W., Parahyanti, E., \& Soemitro, L. J. (2013). Hubungan antara Perceived Organizational Support dan Workplace Well-Being pada Pekerja Pabrik The Relationship between Perceived Organizational Support and Workplace Well-Being among Manufacture Worker. Jurnal Psikologi UI, 1-20.

Silalahi, Ulber. (2015). Metode Penelitian Sosial Kuantitatif. Refika

Soh, M., Zarola, A., Palaiou, K., \& Furnham, A. (2016). Work-related well-being. Health Psychology Open, 3(1). https://doi.org/10.1177/2055102916628380

Sugiyono. (2012). Metode Penelitian Kuantitatif Kualitatif dan REB. Bandung: Alfabeta. 